\title{
DUPLICATION OF INFERIOR VENA CAVA IN RENAL CANCER: A RARE OCCURRENCE
}

\author{
Rahul Agarwal', Prashant Chandra Das², Madhusmita Patro ${ }^{3}$, Puneet Saxena ${ }^{4}$
}

${ }^{1}$ HOD, Department of Surgical Oncology, Jawaharlal Nehru Cancer Hospital, Bhopal.

${ }^{2}$ Senior Resident, Department of Surgical Oncology, Kidwai Memorial Institute of Oncology, Bengaluru.

3Senior Resident, Department of Anaesthesiology, Tata Memorial Hospital, Mumbai.

${ }^{4}$ Consultant, Department of Radiology, Jawaharlal Nehru Cancer Hospital, Bhopal.

\section{ABSTRACT}

Inferior Vena Cava (IVC) duplication is a rare anomaly with an incidence of $0.2-3 \%$, developing from the cardinal veins. It is associated with a host of genitourinary anomalies with the right vena cava being usually dominant. It is of immense clinical importance for a clinician to avoid any diagnostic dilemmas and for planning safe radiological interventions or surgery.

\section{KEYWORDS}

Cardinal Veins, IVC Duplication, Renal Cell Carcinoma.

HOW TO CITE THIS ARTICLE: Agarwal R, Das PC, Patro M, et al. Duplication of inferior vena cava in renal cancer: a rare occurrence. J. Evolution Med. Dent. Sci. 2016;5(51):3348-3349, DOI: 10.14260/jemds/2016/774

\section{INTRODUCTION}

Duplication of Inferior Vena Cava (IVC) though rare is one of the most common congenital anomalies of the vena cava.[1] It is of immense clinical importance for a clinician; be it a radiologist; a vascular surgeon, oncosurgeon or a urologist. Here, we present a case of duplication of IVC that we came across during radical nephrectomy for renal cell carcinoma.

\section{CASE SUMMARY}

A 47-year-old female presented with lump in left abdomen for 1 month associated with dull aching pain, on and off fever and generalized weakness. There was no history of haematuria, loss of appetite or loss of weight. Physical examination revealed no evidence of pallor, icterus, clubbing or pedal oedema. Abdominal examination revealed a lump approximately $12 \times 10 \times 10 \mathrm{~cm}$ in left lumbar region. The lump was bimanually palpable and ballotable. Ultrasonography was suggestive of a left renal mass. A computed tomographic scan of the abdomen revealed a heterogeneously enhancing left renal mass_at midpole measuring $9.9 \times 8.3 \mathrm{~cm}$ with left renal vein thrombosis. Duplication of IVC was noted with the leftsided IVC being predominant [Figure 1, 2, 3]. Interiliac veins were seen communicating with each other at the level of aortic bifurcation. The right and left renal veins were draining into the ipsilateral IVC. Both the IVC united and continued as azygos vein in the thoracic cavity. The left renal vein thrombus was noted to be extending into adjacent left-sided IVC [Figure 2, 3].

She had no medical co-morbidities and all her routine blood investigations were normal. A metastatic workup including contrast tomography of the chest and bone scan were done, which were found to be unremarkable. A left-sided radical nephrectomy was planned. The left renal vein was observed to be draining into the ipsilateral IVC [Figure 4]. Radical nephrectomy and removal of thrombus was done.

Financial or Other, Competing Interest: None.

Submission 27-12-2015, Peer Review 03-06-2016,

Acceptance 09-06-2016, Published 27-06-2016.

Corresponding Author:

Dr. Prashant Chandra Das,

Room: 216, Post Graduate Men's Hostel,

Kidwai Memorial Institute of Oncology,

Bengaluru.

E-mail:dr.munu.das@gmail.com

DOI: 10.14260/jemds/2016/774
The patient had an uneventful recovery. Histopathology revealed clear cell carcinoma at the upper pole of kidney; perinephric fat, hilar, paracaval, paraaortic lymph nodes were tumour free. The patient was kept on regular follow-up and has remained disease free over the 15 months of followup.

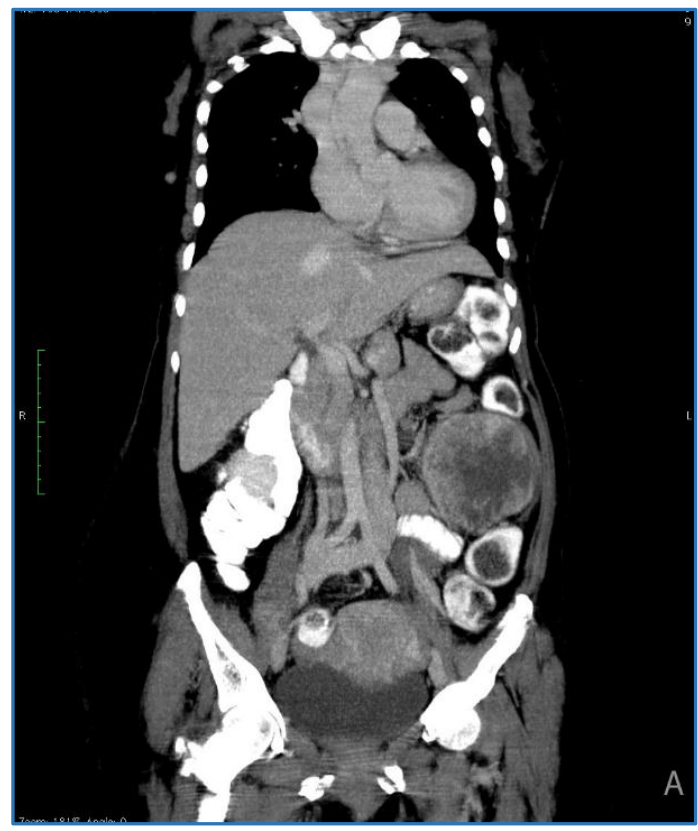

Fig. 1: Coronal Reformate showing Duplication of IVC

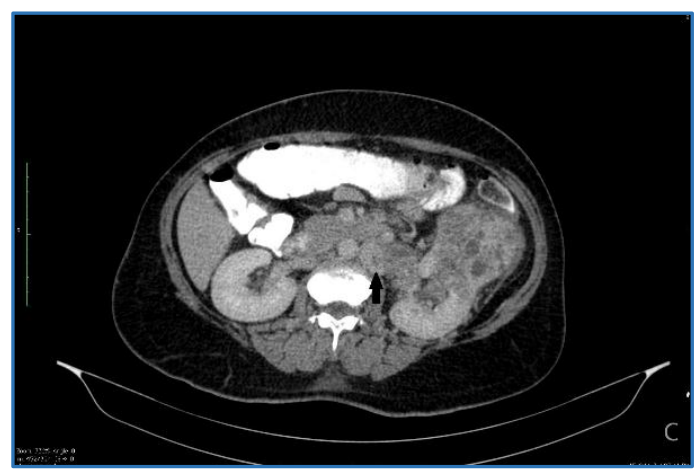

Fig. 2: Axial Reformate showing Duplication of IVC Left-Sided Tumour Thrombus Extending in Ipsilateral IVC (Black Arrow) 


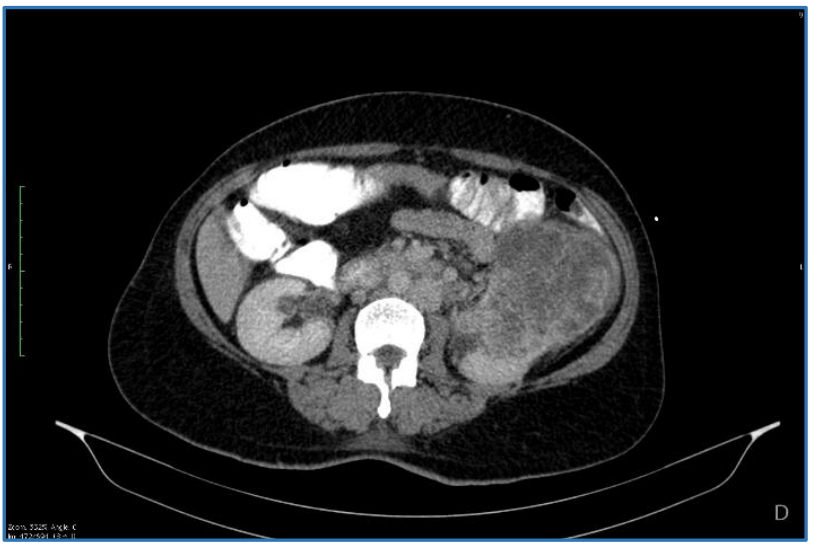

Fig. 3: Axial Reformate showing Duplication of IVC with Each Renal Vein Draining into Ipsilateral IVC

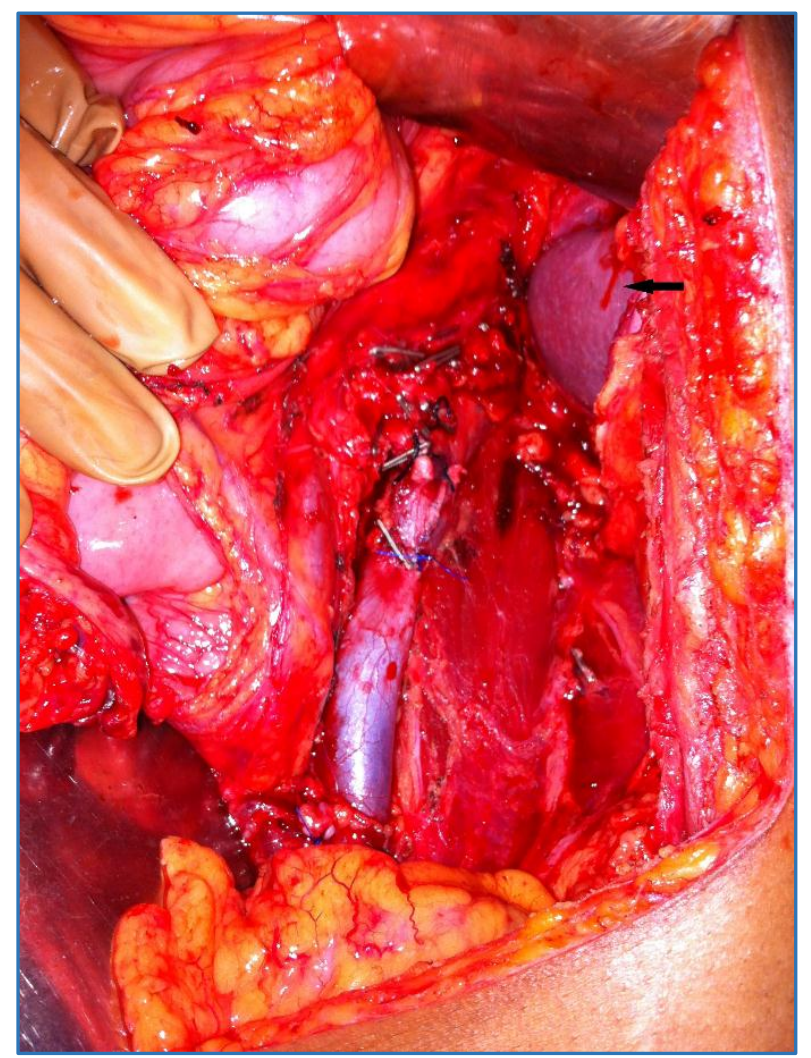

Fig. 4: Post-Nephrectomy Photograph showing Left-Sided IVC with the Bowel having been Mobilised Medially and Spleen (Black Arrow) Visible Superiorly

\section{DISCUSSION}

Duplication of IVC is a rare anomaly with a incidence of 0.2 $3 \%$.[1] The embryogenesis of IVC is a complex process of vessel fusion, regression and formation of midline anastomoses involving three paired venous channels (Posterior cardinals, sub-cardinals and supra-cardinals) occurring during the sixth to eighth week of gestation. First the posterior cardinal vein appears, but regresses completely except the distal part which forms the iliac bifurcation. The paired subcardinal veins are the next to appear with the right subcardinal vein forming the suprarenal segment of IVC and the left subcardinal system regressing. Lastly, the supracardinal veins appear with the right system persisting to form the infrarenal segment of IVC and the left system regressing.[2,3] The right vena cava is usually dominant with the left vena cava joining it in front or behind the aorta at the level of or just above the left renal vein.[4] In our case, the left vena cava was dominant.

The various genitourinary anomalies associated with duplication of IVC are horseshoe kidney, cloacal exstrophy, circum-aortic renal vein known as 'venous collar,' retro-aortic left renal vein. ${ }^{[5,6,7]}$ The exact cause and effect or association between IVC anomalies and genitourinary anomalies is not completely understood. In our case no associated anomaly was seen.

Preoperative diagnosis of a duplicated IVC with a CT or MRI is imperative for planning of a safe radical nephrectomy, to identify the anomalous vessel and differentiate it from lymphadenopathy.[2] The vena caval anomalies tend to be tortuous and dilated requiring utmost vigilance on the part of the operating surgeon in preventing any untoward injury. ${ }^{[8]}$ In our case, no such association was seen.

\section{CONCLUSION}

Duplication of inferior vena cava presents a significant challenge to the treating clinician and should be kept in mind while making a radiological intervention or diagnosis or during surgery. With today's advances in radiology, this anomaly can be easily picked up in imaging studies sparing any inadvertent surprises to the surgeon. To the best of our knowledge, this is the first case of duplication of IVC found in a patient with renal cell carcinoma to be reported in the Indian population.

\section{REFERENCES}

1. Mayo J, Gray R, Louis E, et al. Anomalies of the inferior vena cava. AJR 1983;140:339-45.

2. Mani N, Venkataramu NK, Singh P, et al. Duplication of IVC and associated renal anomalies. Indian J Radiol Imaging 2000;10(3):157-8.

3. Saad KR, Saad PF, Amorim CA, et al. Duplication of the inferior vena cava: case report and a literature review of anatomical variation. J Morphol Sci 2012;29(1):60-4.

4. Gupta RS, uz Zamman W, Srivastava A, et al. Duplication of the inferior vena cava: clinical implication during live donor nephrectomy and the role of preoperative CT angiography. Indian J Urol 2002;18(2):164-6.

5. Muecke EC, Cook GT, Marshall VF. Duplication of the abdominal vena cava associated with cloacal exstrophy. J Urol 1972;107(3):490-7.

6. Aljabri B, MacDonald PS, Satin R, et al. Incidence of major venous and renal anomalies relevant to aortoiliac surgery as demonstrated by computed tomography. Ann Vasc Surg 2001;15(6):615-8.

7. Smith TR, Frost A. Anomalous inferior vena cava associated with horseshoe kidneys. Clin Imaging 1996;20(4):276-8.

8. Downey RS, Sicard GA, Anderson CB. Major retroperitoneal venous anomalies: surgical considerations. Surgery 1990;107(4):359-65. 